\title{
Electronic Literature and the Unmasking of Codes
}

\author{
Ari J. Adipurwawidjana \\ Department of Literature and Cultural Studies, Faculty of Cultural Sciences, Universitas \\ Padjadjaran, Jalan Raya Bandung-Sumedang km 21, Jatinangor, Sumedang 45363, West Java, \\ Indonesia
}

\{adipurwawidjana@unpad.ac.id\}

\begin{abstract}
The cultural materialist approach in literary studies, which treats literary texts as cultural products, has revealed the contribution of literature to social and political formations while at the same time is also produced by them. With the rise of the significance of digital technology, it becomes more apparent that texts, literary or otherwise, are produced and styled by systems of coding, making bare the ideological premises that operate texts. By looking at the technologies previously used to produce texts and particularly the current explorations in electronic literature, this presentation seeks to show codes used to produce texts are ideologically charged.
\end{abstract}

Keywords: code, electronic literature, ideology, cultural materialism, digital technology

\section{INTRODUCTION}

Scott Rettberg, an electronic literature scholar and poet, opens his comprehensive book on electronic literature and its problematics by saying: "Imagine a book. That's easy enough, you're holding one now" [1]. The statement is quite an ironic one for two interrelated reasons. First, it is after all a book about electronic literature, which is available for purchase on not only online sites such as Amazon but also on Google Play. Second, for the purposes of this paper, I am also referring to the electronic version of the book, which I read on my laptop computer, So, I was not holding the book nor will I probably ever. It is, however, clear that the seemingly simple statement, with which Rettberg introduces the topic of his book, instigates the questions that I would like to explore here about how electronic or digital technology has changed the how we may understand literature and to a certain extent also literary studies.

The development in digital technology by the beginning of the 1990s has changed what we mean by reading and writing both as mental and as physical activities. As, perhaps, with any new technology, popular resistance to new practices caused by the implementation of digital technology particularly in literary studies was and still is inevitable. Hayles, for example, remarks that the shift from print to digital technology will, of course, be less than smooth as the practice of literary production and discipline of literary studies have been for half a millennium so accustomed to the conventions of print that the whole field has been practiced with print as the underlying assumption [2]. Similarly, Stein asserts that " $[\mathrm{t}]$ he computer screen's emergence as site for making and distributing poetry tests the public's unquestioned, five-hundred-year-old acceptance of the materiality of the printed page, asking bookworms to rethink the very terms of the reading act" [3]. Because with the advent of digital technology reading, as Stein suggests, entails a 
new set of activities, writing, as the inseparable pairing to reading, consequently, must also reconsider the kinds of activities and spheres in which it is involved. The introduction of digital technology in the humanities, especially literary studies, was initially served as a mere auxiliary, which for the most part, transfers texts previously produced to be hand-written or printed on paper (or other twodimensional media) to digital format as either text or image. Such digitization of existing text involves either the scanning or transcription of those texts, the result of which are the digitized version of literary and academic texts, which now has become indispensable resources for both creative and academic endeavors, through such sites as JSTOR, Project Muse, Project Gutenberg, and the controversial Library Genesis. Similarly, the output of creative writing practices based on the production of texts to appear on the printed page were transferred onto digital platforms either in individual storage or published onto online platforms such as literary websites, electronic magazines, and social media.

This study, however, seeks to focus on those artistic textual endeavors which not only display works online but also explore the new possibilities opened up by digital technology. These explorations include self-reflexive textual manipulations which questions the very workings of texts and textuality. In this sense, these works are at the same time avant-garde experimentations in the creative process and also theoretical investigations in new aesthetics. These cutting-edge literary adventures, so to speak, have been comprehensively inventoried by the Electronic Literature Organization in their online collection, which serves as a both an archive and a hub of various electronic literature projects by various artists, individually and collaboratively [4].

As theoretical investigations, these works of electronic literature carry out the kind of enquiry which Eco employs in his effort to work out the semiotic operations of literary texts [5]. Eco models his analysis after the basic logical formulas commonly used in simple electronic systems. He, for example, attempts to encode and codify the signs put into play in the narrative in both the Book of Genesis and, suggestively, Milton's Paradise Lost [6]. What is important to note for the purposes of this paper is the way Eco attempts to encode the semantic content and value of various linguistic levels, mainly the lexical and the clausal, and even moral value into Yes/No (i.e. 1/0) sequences. As such, Eco's model provide an objective, and in a way secular, decoding method of interpreting signs and the system thereof, which demystifies meaning and its production. It also displays how such coding serve as the method by which the structure of meaning may be formulated. What Eco does with meaning, borrowing the language of applied mathematics in general and information science in particular, is similar to the way Genette takes the grammatical concepts and terminology in order to begin to formulate a model in which narrative structure may be analyzed objectively [7].

The method which Eco initiates demonstrates that such patterns and structures, which literary students and scholar conventionally use, as style and genre may also be understood as code. Davis, for example, in his effort to historicize the novel, places the emergence of the genre in a matrix of prestructures, that is a set of preexisting socio-cultural and aesthetic codes out of which the structure of the new genre was generated [8]. Moving beyond his scientific to formulate meaning and value (semantic, aesthetic, moral, and social) as codes, is Eco's creative dismantling of the ideologies pervasively latent in texts in, for example, his The Name of the Rose (1983), Foucault's Pendulum (1984), and Misreadings (1993), all of which are self-reflexive, metafictional works where texts struggle to their own internal workings. In this paper, I would like to show how particular projects in electronic literature unmasks the surfaces of texts to reveal the codes operating them.

\section{METHODOLOGY}

This study employs the cultural materialist methodological framework in the reading of literary text in which literary works are juxtaposed with other textual materials, known as cotexts, such as related and relevant magazine articles and advertisements or other non-literary texts which addresses similar issues as the work in question. In the case of this paper, the works in electronic literature is set side by side with the codes that generate them. Cultural materialism, 
according to Brannigan [9], functions as the framework with which texts in general are seen as products and functional components in social and political formations. Brannigan further explains that the methodology which cultural materialism offers views the relationship between literature and history not as representational, which assumes history as established truth inscribing meaning on texts. Texts and their co-texts build a discourse as contexts, which forms the understanding of reality; and, therefore, there is a reciprocal relationship between literature and history.

This methodology suits the discussion of the experimentations in electronic literature, for as Hayles explains, digital technology reveals the materiality of texts [10]. The shift from print to digital technology, for Hayles, is more than a mere move from one media to another. Codes inscribed in print, like genetic codes in the human body, are permanent while codes in digital texts are open to modifications, erasures, and additions. As such, digital coding inscribed in electronic texts are "flickering signifiers." It is that unstable condition of codes within electronic texts that provides space for enquiry for the way codes work also in texts laid out in the twodimensional physical page.

\section{FINDINGS AND DISCUSSION}

The Electronic Literature Collection website displays three volumes of projects in electronic literature carried out by artists from all over the world. Volume 1 consists of works collected in 2006, Volume 2 compiles projects collected in 2011, and, the most recent, Volume 3 which includes projects collected in 2016. The Electronic Literature Organization website [11] gives notifications of additions and updates to the works in the three volumes. Based on the form and the media used, Stein identifies two general categories of electronic poetry, namely (1) Video Poetry and (2) New Media Poetry [3]. Video poetry includes works in the form of "docu-video poetry" and "filmic poetry/Cin(E)-poetry." New media poetry consists of "fixed-text, computerbased poetry," "alterable text electronic poetry," and "collaborative/participatory media poetry."

For the sake of the argument to be proposed in this paper, the projects in the Electronic Literature Collection is classified in terms of the kind of textual enquiry that the projects carry out. In that framework the works may be classified into three groups, in which one project may be viewed as belonging to more than one group. The first group focuses on stripping down textuality into its elemental coding operations. The second explores the possibility of incorporating different media into one project. The third seeks to open up new possibilities available in textual production by digital technology. Video poetry, in Stein's classification, generally falls in my second category while the explorations of the first and third groups are mostly carried out by projects in New Media Poetry. However, the projects collected in the Electronic Literature website do not always fall under the genre of poetry. Some define themselves as stories while other resist being defined as a recognized genre at all. This is understandable, as these projects attempts to move beyond the limitations of print literature based on which our common understanding of literary genre is constructed.

The effort to strip down the textuality of literary works as codes not only resemble the kind of endeavor that Eco tries to do theoretically but also that which had been carried out under the auspices of literary modernism carried out by poets and fiction writers in the early twentieth century. Such attempts in Modernist literature were in general carried out in two ways, namely minimalist writing by focusing on a single image or symbol and the technique known either as automatic writing or as stream of consciousness. The example of the former is the poetic work of Ezra Pound and Archibald MacLeish. Later, this project is continued by such American Beat poets as William Carlos Williams, Jack Kerouac, and Allen Ginsberg. The latter is apparent in 
the works of Gertrude Stein, William Faulkner, Virginia Woolf, and especially James Joyce. This project is later continued also by the poets of the Beat Generation.

The Modernist effort to strip language to its bare elements towards what may be understood as "pure language" is inevitably confronted by the physicality or materiality of language. Amiran comments that "[w]hen modernism seeks mere materialism..., it approaches nonsense, yet each attempt to make nonsense a pure experience, separate from referentiality, or the physical property of mind, or the generative ground for figural meaning - all aspects of the fantasy of matter-exposes the desire for it as a refuge for textuality" [12]. Thus, language is imagined and understood to be "physical and spatial." This so-called "approach to nonsense" in the quest for "pure language" was already apparent in the nineteenth-century classic Alice in Wonderland by Lewis Carroll, which is the very reason the Electronic Literature Collection adds the mathematical-linguistic experimentations by Lewis Carroll as the precursor to electronic literature.

One project worthy of note in terms of delving into the materiality of language is Dan Waber's "Strings," in which "a scrawl that has a life of its own, embodying certain human activities (arguing, flirting, laughter) in the form of animated lines of handwriting that pull themselves into the shape of ideas" [13]. This project is not a mere gimmick utilizing Macromedia Flash to present animated handwriting out of scribbled lines. It is a series of logical enquiries which ultimately problematizes the basic logical operations we have taken for granted. It consists of a series of eight Flash animations, respectively entitled "argument," "argument2," "flirt," "flirt (cntd)," "haha," "youandme," "arms," and "poidog." It begins with the scrawled string squirming and forming the words "yes" and "no" as the basic elements of argument and code, but soon produces "maybe" in the process, complicating simple logic. As the argument develops into the next parts of the series, "yes," "no," and "maybe" become indistinguishable as the essentials of logic and code evolves into the very human complex elements such as laughter and the concepts of self and other. Finally, the physicality of the lines that form the representation of those human concepts become starkly apparent, and ends with the conclusion that "words are like strings that pull out of my mouth." Yet, the potential of the final statement of providing figurative meaning is undercut by the sheer physicality of the hand-writing as an animated visual figure in the most literal sense.

Just as the Modernist legacy of decomposing language into its visual physicality later develops into the shedding the surfaces of language into its elemental sounds which characterizes the Beat movement, underlining not only the textuality but also the orality of poetry, a number of the projects collected in the Electronic Literature collection focus on the sonic quality of language. Jörg Piringer's "Sound Poems," for example, highlights the nature of poetic language as the interaction of linguistic sounds and images [14]. Piringer's project consists of three parts, entitled "gravity and reflection," "predator vs. prey," and "food chain," each representing a particular form of interaction. In "gravity and reflection" a random letter is produced at the point the cursor is pointed and clicked on a particular spot of the available field. The letter falls to the bottom of the field, and as soon as it touches the edge of the field, whether when it initially falls, or when it bounces up and hits the left or right edges, it makes a sound particular to the letter but does not correspond to the linguistic sound as it is commonly accepted. Thus, the poem establishes a one-to-one correspondence between image and sound as it is required in language but at the same time demonstrates the Saussurean notion of arbitrariness. The relationship between sound and image is maintained also in "predator vs. prey" but the nature of the relationship is different. The "reader" is given the option of seven letters, four are vowels: A, I, E, and U and three consonants M, R, and S. Following the reader's clicking a letter box, a letter moves and maneuvers within the field. The vowels behave like predators pursuing 
the consonants, and as soon as a vowel manage to reach a consonant both disappear. Unlike "gravity and reflection," the sound produced with the appearance and movement of the letter corresponds with the generally accepted sound associated with the letter. For example, the letter $\mathrm{E}$ appears and moves accompanied by the continues production of the sound [e], and such is also the case with letter M's being attended by the sound [m]. Finally, in "food chain," preexisting letters and those whose appearance is prompted by the readers click move, collide and bounce off each other producing sounds.

The second category explores the possibilities of using various modes of representation in one work. For instance, Ingris Ankerson and Megan Sapnar's "Cruising" combines the typographic and auditory elements of language (i.e. writing and speech) with the elements of other forms of art, namely still images, moving pictures, and music [15]. Each component seems to have a specific, autonomous aesthetic function in that none serves as a mere illustration of the other except, perhaps the music. This group of electronic literature is limited in the reader's interaction and participation. However, this type of electronic literature reminds us of the unmanageability and fixedness of the conventional text (as well as other conventional art forms such as the painting, the sculpture, the photograph, the film, and, to a certain extent also, the dance and theater). Scott Rettberg's "Frequency," for example, intentionally makes a list of the most commonly used words in English and manually—without the help of machines - produces a series of poems using those words. The poems, syntactically and graphically arranged, appear is sequence, one after the other, automatically after several minutes without the interaction or participation of the reader [16].

The most reflexive of the three categories is the last where the operative code is revealed as the text is received by the reader. An example of this would be Bjørn Magnhildøen's "Plaintext Performance," in which the plaintext coding is interspersed with conventional text with actual semantic content [17]. In this work the metadata of the text, the text proper, and the code all appear on the same single page on the screen. It begins with:

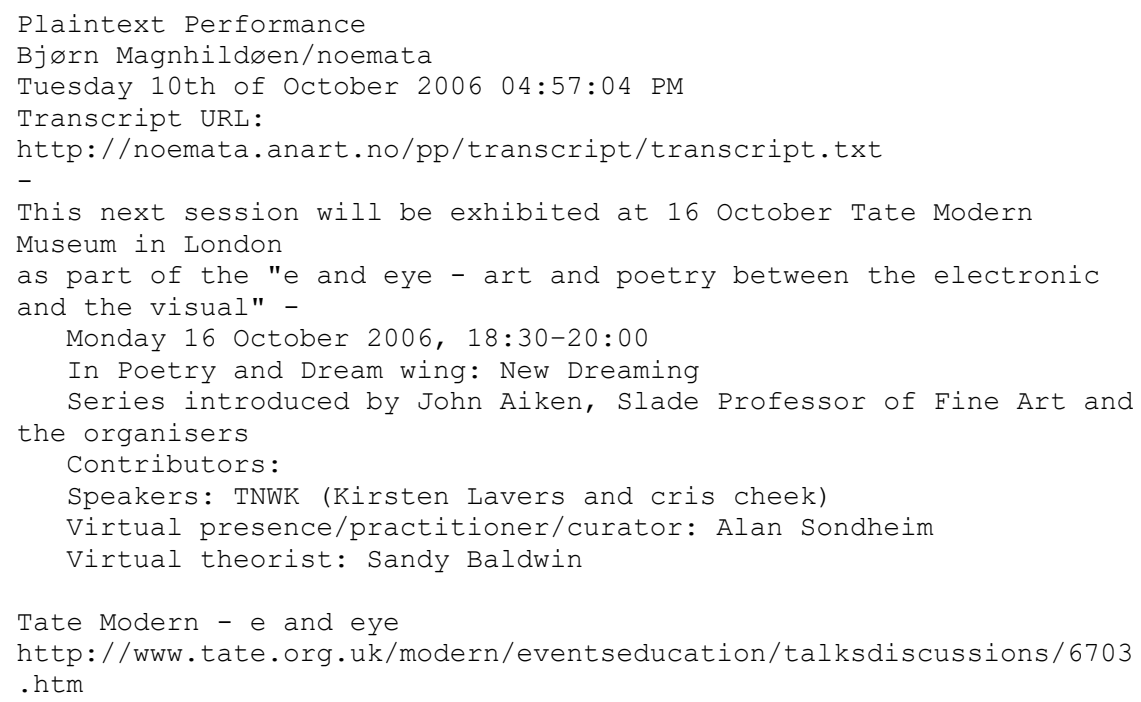

Then, it proceeds with the kind of text which resembles the stripped-down, nonsense text as exemplified in the first group, but in a more extreme manner: 


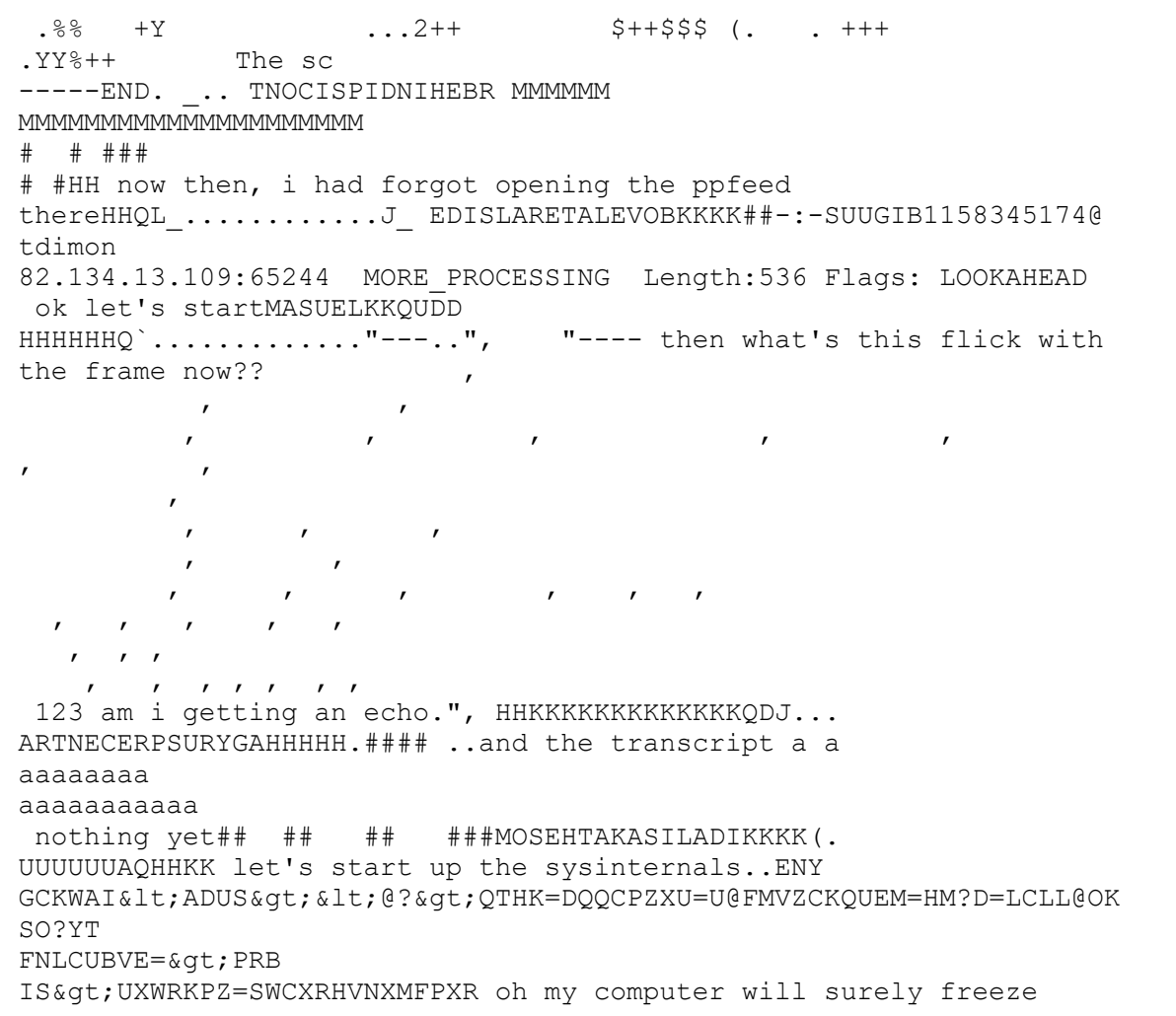

The text not only represents but more importantly performs the speaker's stumbling and struggling with the languages of both human and machine. The reader also is forced to fumble through the text as the text automatically and continuously scrolls down and at odd moments jumps a few lines up, driven by codes readily apparent at the surface of the performance. This work reveals the possibilities (and simultaneously the limitations) of writing and reading opened up by the availability of digital technology.

One of the most significant new feature to textuality made available by digital technology is the "hypertext." Because the notion of the hypertext is very much the product of digital technology which hardly appears in the printed text, there is a lack of clarity about what it actually means. Richard Holeton's "Frequently Asked Questions about 'Hypertext" showcases a fictional poem entitled "Hypertext" authored by a fictional character named Alan Richardson, with a series of hypertext links to FAQs pertaining to the poem [18]. This poem performs hypertext and at the same time, through parody, questions the idea. On the other hand the collaborative work by Scott Rettberg, William Gillespie, Dirk Stratton, and Frank Marquardt entitled "The Unknown" anthologizes the works of the collaborating artists but providing hypertext links at varied words and phrases of each work to other works [19]. This project resists the kind of linear reading forced by text on a page and accommodate the kind of reading which many of us have grown to be accustomed to as we now click on a hyperlink before we finish reading a page of an online text.

Probably the most radical of all the works in the three volumes of the Electronic Literature Collection is Ramsay Nasser's "قلب" or “qalb" (Arabic for "heart”) which is a programming language totally written in Arabic with Arabic script [20]. It is an attempt to resist the 
dominant use of Roman characters and the English language in computer programming. The project is poetic and at the same time very technical as the work of art is the programming language itself. This project reveals that even the language of machines is politically charged by the colonial course of recent human history.

\section{CONCLUSION}

Electronic literature prompts us to rethink the very nature of literature and literary theory. New forms and formulas as well as methodological procedures need to be devised in literary studies which take into account the various technologies which have been used to produce literary texts throughout human history and particularly that phase in which occurred the shift from the technology of print-on-paper to that of virtual display on LCD screens. This shift not only brings about a change in the way text are produced and offered to readers but it also prompts the change in the way the human body behaves toward texts and the way human beings interact with each other.

As we come to the realization that technological transformations affect the behavior humans and the human body, we are prompted to think about the extent to which we are separated from or linked to the technologies we develop. We are compelled to think about the limits of being human and begin to think about our being posthuman. On this issue Hayles remarks: "the posthuman implies a coupling so intense and multifaceted that it is no longer possible to distinguish meaningfully between the biological organism and the informational circuits in which it is enmeshed" [10]. While the Electronic Literature Collection has brought to our attention the possibilities and limitations made available by digital technology, as I have discussed elsewhere, we are still left with vast unexplored territory where the biological and biotic system interface with electronic informational circuits [21]. After all, even if we consider the Turing machine as the beginning of digital technology, eight decades of digital technology still operates under the shadow of five centuries of print and more under various forms of textual technologies.

\section{References}

[1] S. Rettberg. Electronic Literature. Cambridge, UK, Polity Press, 2019.

[2] N. K. Hayles. "Print Is Flat, Code Is Deep: The Importance of Media-Specific Analysis." Poetics Today, vol. 25, no. 1, pp. 67-90, 2004.

[3] K. Stein. Poetry's Afterlife: Verse in the Digital Age. Ann Arbor, MI, USA: Univ. of Mich. Press, 2010

[4] Electronic Literature Organization. Electronic Literature Collection. http://collection.eliterature.org/. Accessed 14 April 2019.

[5] U. Eco. The Role of the Reader. Bloomington, IN, USA: Indiana U. P., 1979.

[6] U. Eco. Theory of Semiotics. Bloomington, IN, USA: Indiana U. P.., 1976.

[7] G. Genette. Narrative Discourse: An Essay on Method. Ithaca, NY: Cornell U. P., 1980.

[8] L. J. Davis. Factual Fictions: The Origins of the English Novel. New York, NY, USA: Columbia U. P., 1983

[9] J. Brannigan, . New Historicism and Cultural Materialism. London, UK: Macmillan, 1998.

[10] N. K. Hayles, "Virtual Bodies and Flickering Signifiers," October, vol. 66, pp. 69-91, 1993.

[11] Electronic Literature Organization. www.eliterature.org. Accessed 14 April 2019. 
[12] E. Amiran. Modernism and the Materiality of Texts. New York, NY, USA: Cambridge U. P., 2016.

[13] D. Waber. "Strings." Electronic Literature Collection. Volume 1. http://collection.eliterature.org/1/works/waber_strings.html. Accessed 14 April 2019.

[14] J. Piringer. "Sound Poems." Electronic Literature Collection. Volume 2. http://collection.eliterature.org/2/works/piringer_soundpoems.html. Accessed 14 April 2019.

[15] I. Ankerson and M. Sapner. "Cruising." Electronic Literature Collection. Volume 1. http://collection.eliterature.org/1/works/ankerson_sapnar_cruising.html. Accessed 14 April 2019.

[16] S. Rettberg. "Frequency." Electronic Literature Collection. Volume 3. http://collection.eliterature.org/3/work.html?work=frequency. Accessed 14 April 2019.

[17] B. Magnhildøen. "Plaintext Performance." ." Electronic Literature Collection. Volume 2. http://collection.eliterature.org/2/works/magnhildoen plaintextperformance.html. Accessed 14 April 2019.

[18] R. Holeton. "Frequently Asked Questions about 'Hypertext'." Electronic Literature Collection.

Volume http://collection.eliterature.org/1/works/holeton_frequently_asked questions_about hy pertext/index.html. Accessed 14 April 2019.

[19] S. Rettberg, W. Gillespie, D. Stratton, and F. Marquardt. "The Unknown." Electronic Literature Collection. Volume 2. http://collection.eliterature.org/2/works/rettberg_theunknown.html. Accessed 14 April 2019.

[20] R. Nasser. "قلب" Electronic Literature Collection. Volume 3. http://collection.eliterature.org/3/works/arabic-programming-language/index.html. Accessed 14 April 2019.

[21] A. J. Adipurwawidjana. "Di Mana Tubuh Berakhir?: Performa Badani, Lingkungan, dan Teknologi ("Where Does the Body End?: Bodily Performance, the Environment, and Technology". In A. Priyatna and L. Manggong, Eds. Tubuh dan Ideologi, in Indonesian). Yogyakarta, Indonesia: Arti Bumi Intaran, pp. 35-56, 2018, 